\title{
Modulation of the startle response in verbal aggressors: differences among stimuli with distinct affective social content
}

\author{
Carlos Gantiva ${ }^{1}$, Diana Díaz ${ }^{1}$, Ingrid Ospina ${ }^{1}$, Adriana Gutierrez ${ }^{1}$, Tania Romo-Gonzalez ${ }^{2}$ \\ 1. Universidad San Buenaventura, Bogota, Colombia \\ 2. Universidad Veracruzana, Veracruz, México
}

\begin{abstract}
The emotional response to socially affective stimuli is an important variable to understand aggression. Research is lacking on the psychophysiological basis of verbal aggressiveness that would allow the identification of these emotional responses. The aim of the present study was to investigate modulation of the startle response in verbal aggressors during the presentation of visual stimuli with different affective social content. Acoustic startle probes were administered to 29 verbal aggressors and 28 non-verbal aggressors while viewing slides from the International Affective Picture System, which contains sexual, filial, neutral, unpleasant, and suffering of others pictures. Verbal aggressors showed a low startle response to sexual pictures compared with non-verbal aggressors and a potentiated startle response to neutral pictures compared with unpleasant, filial, and suffering of others pictures. These differences were observed among women. Based on previous studies, the present results may be explained by high testosterone levels, low cortisol levels, and moral disengagement exhibited by verbally aggressive women. Keywords: startle response, aggression, affective startle modulation, emotion.
\end{abstract}

Received 05 March 2014; received in revised form 05 May 2014; accepted 14 May 2014. Available online 27 June 2014.

\section{Introduction}

Aggressive behavior results from a relationship between environmental and personal factors (Roberton, Daffern, \& Bucks, 2012) originating from interactions between inputs (i.e., persons, attributes, and situations), mediating pathways (i.e., cognitive, affective, and arousal), and outcomes (i.e., decisions and actions; Anderson \& Bushman, 2002). Some of the manifestations of aggressive behavior, such as verbal aggressiveness, are positively associated with mental disorders and psychosocial maladjustment and negatively associated with prosocial behavior, especially in adolescence (Card, Stucky, Sawalani, \& Little, 2008; Loeber \& Hay, 1997).

Research on the biological basis of personality traits and mental disorders has shown a relationship between

Carlos Gantiva, Diana Díaz, Ingrid Ospina, and Adriana Gutierrez, Department of Psychology, University of San Buenaventura, Bogota, Colombia. Tania Romo-Gonzalez, Area de Biología y Salud Integral, Instituto de Investigaciones Biológicas, Universidad Veracruzana, México. Correspondence regarding this article should be directed to: Carlos Gantiva, Cr 8 H \# 172-20, Bogotá, Colombia. Phone: +57(1) 6671090. Fax: +57(1) 6671090. E-mail: cgantiva@usbbog.edu.co, cgantiva@gmail.com psychophysiological variables and psychopathic traits (Anderson, Wan, Young, \& Stanford, 2011; Casey, Rogers, Burns, \& Yiend, 2013), anxiety (Delgado, Guerra, Perakakis, Mata, Perez, \& Vila, 2009; Garner, Clarke, Graystone, \& Baldwin, 2011), tobacco consumption (Cui et al., 2012; Engelmann, Gewirtz, \& Cuthbert, 2011; Muñoz, Idrissi, Sánchez-Barrera, Fernández-Santaella, \& Vila, 2013; Muñoz, Viedmadel-Jesus, Fernández-Santaella, Peralta-Ramírez, Cepeda-Benito, \& Vila, 2010), and externalizing traits (Baskin-Sommers, Curtin, Larson, Stout, Kiehl, \& Newman, 2012), among others. One of the most frequent psychophysiological outcomes is a change in the modulation of the startle reflex. Most healthy individuals exhibit a potentiated startle response to an acoustic startle probe when viewing pictures with high negative emotional content and an inhibited startle response when viewing pictures with high positive emotional content (Bradley, Codispoti, Cuthbert, \& Lang, 2001; Bradley \& Lang, 2000). Nevertheless, individuals with maladaptive personality traits or mental disorders exhibit differences in this pattern of responses to stimuli related to their pathology (Kashdan, Adams, Read, \& Hawk, 2012; Lang, Davis, \& Öhman, 2000).

Research on psychophysiological responses in aggressors has focused specifically on the arousal dimension. For example, Choi et al. (2011) found that 
the level of skin conductance increased significantly when aggressive people were exposed to pictures with aggressive content. Similarly, Reuter, Netter, and Janke (2003) found that people with high scores in psychoticism/aggressiveness (assessed by the EPQ-R [(Eysenck \& Eysenck, 1975)] reported that violent erotic stimuli were more erotic and interesting compared with subjects with low scores in psychoticism/ aggressiveness. Gower and Crick (2011) identified a relationship between low heart rate and blood pressure with physical and relational aggression. These results suggest a link between aggression and the emotional response.

Recently, our group studied emotional responses (i.e., valence, arousal, and dominance) in persons with aggressive traits while they viewed pictures that presented physical aggression, the suffering of others, and filial and sexual scenarios. To evaluate the dimensions of emotion, we employed the SelfAssessment Manikin. The results showed that people with different aggressive traits, including verbal aggression, valued sexual pictures as more pleasant and exhibited more arousal than people without any aggressive trait. No significant differences were found for the other picture categories (Gantiva et al., 2014). This indicates a relationship between aggression and the emotional response to stimuli with sexual content. Notably, when this same analysis was performed separately for men and women, only women with aggressive traits had a significantly different response to sexual pictures (Gantiva et al., 2014). The latter results are consistent with previous reports in which women and men differed in aggressive behavior (Archer, 2004; Bjorkqvist, Osterman, \& Kaukiainen, 1992; Crick \& Grotpeter, 1995; Hess \& Hagen, 2006; Salmivalli, Kaukiainen, \& Lagerspetz, 2000).

Notwithstanding the previous results, no studies have evaluated the startle response to pictures with different affective content in aggressive people, especially in people with high levels of verbal aggression, or gender differences in the startle response in aggressive people. Such studies could allow drawing conclusions about the motivational states that aggressors experience when exposed to these stimuli.

Studies in this area have only focused on people with psychopathic traits (Anderson et al., 2011; Rothemund et al., 2012) or anger traits (Amodio \& Harmon-Jones, 2011; Peterson \& Harmon-Jones, 2012). The present study was designed to investigate the relationship between verbal aggressiveness and the startle response in men and women while the subjects viewed pictures with different social affective content.

\section{Methods}

\section{Participants and screening measures}

Fifty-seven individuals, including 29 men (18-27 years old, $M=23.5$ years, $S D=2.98$ years) and 28 women (21-29 years old, $M=25.3$ years, $S D=2.95$ years) participated in the study. The participants were recruited from different locations in Bogota, Colombia. The exclusion criteria included self-reported auditory deficits, uncorrected visual deficits, a history of head trauma, or a major neurological disorder.

The participants were selected based on their average score on the Buss-Perry Aggression Questionnaire verbal aggression scale (Buss \& Perry, 1992). Individuals with a score greater than the 70th percentile on the verbal aggression scale were included in the verbal aggression group, using norms separately for men and women. The verbal aggression group $(n=29,15$ males) had an average score of $3.86(S D=.57)$. The non-verbal aggression group ( $n=28,14$ males) had an average score of $2.40(S D=.50)$. The difference in the scores on the verbal aggression scale was significantly different between groups $\left(t_{55}=-10.27, p<.001\right)$. No significant differences were found between men and women $\left(t_{26}=.29, p=.77\right.$, and $t_{27}=-.27, p=.78$, respectively). The study was approved by the University of San Buenaventura Review Board, and the subjects provided written informed consent.

\section{Stimuli and procedure}

To assess the verbal aggressors' emotional response to social stimuli with different valence, 24 pictures were chosen (four sexual, five neutral, five unpleasant, five filial, and five suffering of others) from the International Affective Picture System ${ }^{1}$ (Lang, Bradley, \& Cuthbert, 2008) according to the Colombian normative ratings (Gantiva, Guerra, \& Vila, 2011). The pictures were presented for $6 \mathrm{~s}$ on a 19-inch flat screen monitor located approximately $60 \mathrm{~cm}$ from the subject in three counterbalanced blocks of 24 slides each. Within each block, the pictures were presented in a random order, and the intertrial interval (ITI) varied randomly between 10 and $14 \mathrm{~s}$. The startle probes consisted of $50 \mathrm{~ms}, 90$ $\mathrm{dB}$ white noise bursts with an instantaneous rise time, delivered 4-5.5 $\mathrm{s}$ after picture onset. The startle probes were presented randomly in half of the trials in each category and during two ITIs.

\section{Apparatus and physiological response measurement}

A computer that ran LabChart 7.3 software (AD Instruments: Sydney, Australia) and a computer that ran E-Prime 2.0 software (Psychology Software Tools: Pittsburgh, PA, USA) were used to control data acquisition and stimulus events, respectively. The eyeblink component of the startle response was measured via $4 \mathrm{~mm} \mathrm{Ag} / \mathrm{AgCl}$ electrodes over the left orbicularis oculi muscle (Blumenthal, Cuthbert, Filion, Hackley, Lipp, \& van Boxtel, 2005). Electromyographic (EMG) activity was recorded using a sampling rate of 1000

1 The IAPS codes for the pictures were the following: sexual (4693, $4668,4698,4676)$, neutral $(7026,7512,7504,7018,7041)$, unpleasant $(2683,6555,1525,3213,8485)$, filial $(4597,4616,2155,2299,4622)$, suffering of others $(2095,2375.1,6315,6520,9163)$. 
$\mathrm{Hz}$ and $10-500 \mathrm{~Hz}$ frequency band filter, rectified and integrated with a time constant of $20 \mathrm{~ms}$ using Powerlab 26T (ADInstruments, Dunedin, New Zealand). The startle blink magnitude was defined as the first maximum increase in the EMG activity of the orbicularis oculi within a time interval of $20-150 \mathrm{~ms}$ after startle probe onset (Blumenthal et al., 2005). Based on this, the mean EMG of the $20 \mathrm{~ms}$ baseline that directly preceded the onset was subtracted to calculate the startle amplitude.

A total of $3.2 \%$ of all of the trials for the participants were excluded because of unstable baseline activity $(>2$ SDs above the mean within-subject baseline) or outlier responses ( $>3$ SDs above the mean startle magnitude within the picture category for each subject; Cui et al., 2012). To correct for large individual variability in blink magnitude, eye-blink reflex magnitudes were T-transformed within-subjects.

\section{Statistical analysis}

To examine the effect of verbal aggression and picture category on the magnitude of the startle reflex, we used repeated-measures analysis of variance (ANOVA; $2 \times 2$ $\times 5)$ as implemented in the general linear models in SPSS 20.0 software for Windows, with startle magnitude as the dependent variable, Group (verbal aggressors and nonverbal aggressors) and Sex as the between-subject factors, and Picture (sexual, neutral, unpleasant, filial, and suffering of others) as the within-subjects factor. GreenhouseGeisser correction was used to correct any violation of sphericity in the repeated-measures factors. Post hoc analyses of the mean values were performed using paired multiple comparisons adjusted with Bonferroni correction. The level of significance was set at .05 for all of the analyses, and the partial eta squared $\left(\eta_{p}^{2}\right)$ is also presented.

\section{Results}

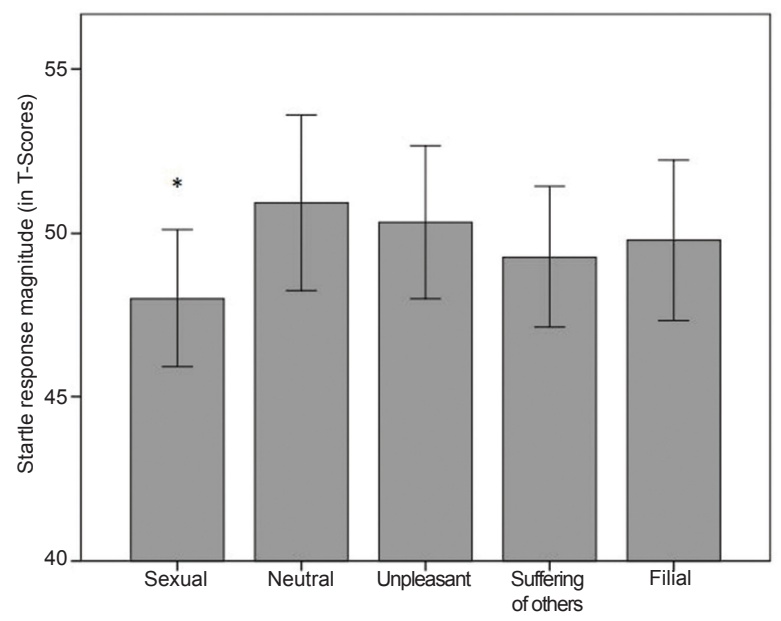

Figure 1. Modulation of eye-blink startle during the visualization of sexual, neutral, unpleasant, suffering of others, and filial pictures (bars represent standard error of the mean). ${ }^{*} p<.05$.

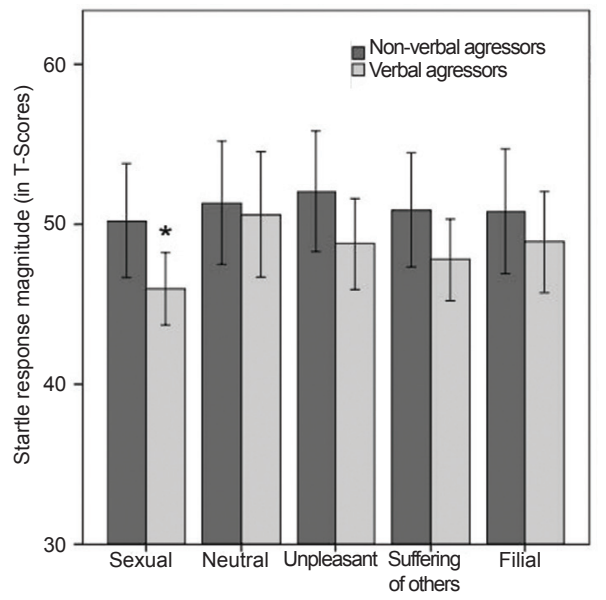

Figure 2. Magnitude of the startle response elicited in verbal aggressors and non-verbal aggressors as a function of picture category (bars represent standard error of the mean). ${ }^{*} p<.05$.

The ANOVA of the startle reflex revealed a significant main effect of Picture $\left(F_{4,21}=15.27, p<.0001, \eta_{p}{ }^{2}=.22\right)$. Sexual pictures significantly attenuated the EMG amplitude compared with neutral $(p=.001)$, unpleasant $(p<.001)$, filial $(p<.05)$, and suffering of others pictures $(p<.01)$. Startle was inhibited during filial pictures compared with neutral pictures $(p<.05)$, and unpleasant pictures elicited a greater startle response than suffering of others pictures $(p<.05$; Figure 1$)$.

A significant Group $\times$ Picture interaction was found $\left(F_{4,22}=4.83, p<.05, \eta_{\mathrm{p}}{ }^{2}=.08\right)$. The Bonferroni post hoc comparisons revealed greater startle attenuation in response to sexual pictures in verbal aggressors compared with non-verbal aggressors $(p<.05)$. Additionally, in non-verbal aggressors, startle during unpleasant pictures was potentiated relative to filial pictures $(p<.05)$. The startle responses to sexual pictures in verbal aggressors were generally inhibited compared with neutral, unpleasant, filial, and suffering of others pictures (all $p<.01$ ). Moreover, neutral pictures elicited

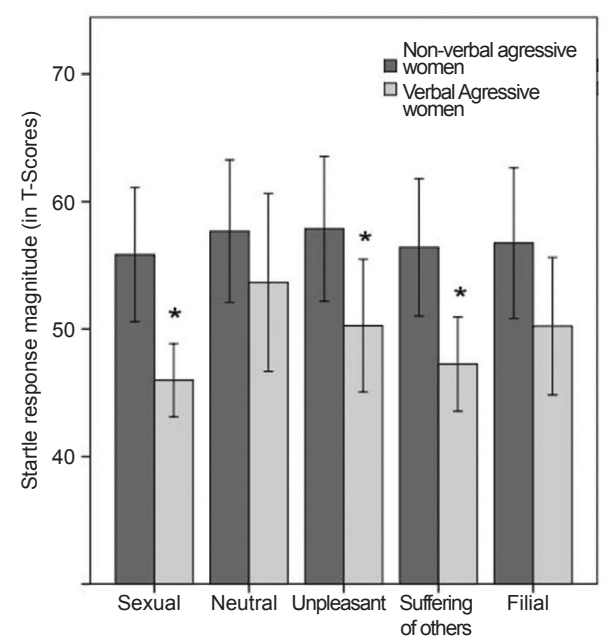

Figure 3. Magnitude of the startle response elicited in verbally aggressive women and non-verbally aggressive women as a function of picture category (bars repreent standard error of the mean). ${ }^{*} p<.05$. 
a greater startle response than sexual, unpleasant, filial, and suffering of others pictures (all $p<.05$; Figure 2 ).

A significant Group $\times$ Sex $\times$ Picture interaction was found $\left(F_{4,21}=3.21, p=.04, \eta_{\mathrm{p}}{ }^{2}=.05\right)$. Bonferroni post hoc comparisons revealed that the greater inhibition of the startle response in verbal aggressors while viewing sexual pictures was observed exclusively in women $(p<.001)$. Additionally, the startle response was less in female verbal aggressors while viewing unpleasant $(p=.01)$ and suffering of others pictures $(p=.001)$ compared with female non-verbal aggressors (Figure 3). Interestingly, in the non-verbal aggression group, significant differences were always found between men and women in all of the picture categories (all $p<.001$ ), whereas no gender differences were found in the verbal aggression group (all $p>.05$ ).

\section{Discussion}

The objective of the present study was to analyze the interaction between verbal aggressiveness and the affective social content of visual stimuli in the modulation of the startle reflex. Previous studies showed that people inhibit the startle response to stimuli with high positive emotional content and increase the startle response to stimuli with high negative emotional content, making the startle reflex a reliable indicator of motivational system activation (appetitive or defensive; Bradley \& Lang, 2000).

The results showed that sexual pictures inhibited the startle response compared with the other picture categories, and unpleasant pictures generated a greater startle response compared with sexual and suffering of others pictures. These were expected results because sexual and unpleasant pictures result in the highest arousal scores (Gantiva et al., 2011; Lang et al., 2008), and the level of arousal has been shown to be a determining factor in the modulation of the startle response (Bradley et al., 2001).

An interesting finding was the significant difference in the inhibition of the startle response to sexual pictures in the verbal aggression group compared with the non-verbal aggression group, specifically in women. Verbally aggressive women exhibited more activation of the appetitive motivational system in response to visual stimuli with sexual content compared with nonverbally aggressive women. Additionally, in the group of non-verbal aggressors, men significantly inhibited more of the startle response to sexual pictures than women $(p<.001)$, whereas no significant differences were observed in the verbal aggression group ( $p=$ $.95)$. These results show a strong relationship between aggressiveness and sexual behavior, which has been explained in other studies by an increase in testosterone and low cortisol levels in aggressive women (Geniole, Carré, \& McCormick, 2011; Montoya, Terbug, Bos, \& van Honk, 2012; Sánchez-Martín et al., 2011; Wilson, 1997). Therefore, women with high testosterone and low cortisol levels may have higher levels of aggression and greater activation of the appetitive motivational system in response to stimuli with sexual content, characteristics that are typically more common in men.

In verbal aggressors, neutral pictures generated a potentiated startle response compared with unpleasant and suffering of others pictures. Similar results have been found in psychopaths (Casey et al., 2013; Patrick, Bradley, \& Lang, 1993). These results are striking when considering that three of the five unpleasant pictures were human or animal attacks, which would be explained by activation of the appetitive motivational system in this group (Bradley et al., 2001; Bradley \& Lang, 2000). Another explanation for this phenomenon in verbal aggressors could be that they had moral disengagement. Previous studies reported that moral disengagement is associated with inhibition of the startle reflex in response to unpleasant pictures (Stanger, Kavussanu, Willoughby, \& Ring, 2012). Other studies reported a lower intensity of negative emotions among soldiers and prisoners of war when they listened to stories of physical abuse (Aquino, Reed, Thau, \& Freeman, 2007).

In summary, the present investigation of startle modulation revealed greater inhibition of the startle response to sexual pictures in verbally aggressive women and an absence of the potentiated startle response to unpleasant and suffering of others pictures in verbal aggressors. This suggests that verbally aggressive women have greater activation of the appetitive motivational system in response to sexual stimuli, which may be related to high testosterone and low cortisol levels. Moreover, activation of the appetitive motivational system in response to unpleasant and suffering of others pictures demonstrated moral disengagement in verbal aggressors, which is positively related to antisocial behavior because it reduces the emotional response that occurs when a person is linked to antisocial behaviors or when he or she observes the suffering of another person (Bandura, 1991).

Finally, some limitations should be considered. Although the startle response is one of the most studied psychophysiological measures with valid and reliable results in psychiatry (Grillon \& Baas, 2003), future studies should incorporate additional measures, such as heart rate or the postauricular reflex.

\section{References}

Amodio, D., \& Harmon-Jones, E. (2011). Trait emotions and affective modulation of the startle eyeblink: on the unique relationship of trait anger. Emotion, 11(1), 47-51.

Anderson, C. A., \& Bushman, B. J. (2002). Human aggression. Annual Review of Psychology, 53, 27-51.

Anderson, N. E., Wan, L., Young, K. A., \& Stanford, M. S. (2011). Psychopathic traits predict startle habituation but not modulation in an emotional faces task. Personality and Individual Differences, $50,712-716$

Aquino, K., Reed, A., 2nd, Thau, S., \& Freeman, D. (2007). A grotesque and dark beauty: how moral identity and mechanisms of moral disengagement influence cognitive and emotional reactions to war. Journal of Experimental Psychology, 43, 385-392. 
Archer, J. (2004). Sex differences in aggression in real-world settings: a meta-analytic review. Review of General Psychology, 8, 291-322.

Bandura, A. (1991). Social cognitive theory of moral thought and action. In: W. M. Kurtines, \& J. L. Gewirtz (Eds.), Handbook of moral behavior and development: theory, research, and applications (pp. 71-129). Hillsdale, NJ: Lawrence Erlbaum.

Baskin-Sommers, A. R., Curtin, J. J., Larson, C. L., Stout, D., Kiehl, K. A., \& Newman, J. P. (2012). Characterizing the anomalous cognition-emotion interactions in externalizing. Biological Psychology, 91, 48-58.

Bjorkqvist, L., Osterman, K., \& Kaukiainen, A. (1992). The development of direct and indirect aggressive strategies in males and females. In: K. Bjorkqvist, P. Niemelae (Eds.), Of mice and women: aspects of female aggression (pp. 51-64). San Diego: Academic Press.

Blumenthal, T. D., Cuthbert, B. N., Filion, D. L., Hackley, S., Lipp, O. V., \& van Boxtel, A. (2005). Committee report: guidelines for human startle eyeblink electromyographic studies. Psychophysiology, 42, 1-15.

Bradley, M. M., Codispoti, M., Cuthbert, B. N., \& Lang, P. J. (2001). Emotion and motivation: I. Defensive and appetitive reactions in picture processing. Emotion, 1(3), 276-298.

Bradley, M. M., \& Lang, P. J. (2000). Affective reactions to acoustic stimuli. Psychophysiology, 37, 204-215.

Buss, A. H., \& Perry, M. (1992). The aggression questionnaire. Journal of Personality and Social Psychology, 63, 452-459.

Casey, H., Rogers, R. D., Burns, T., \& Yiend, J. (2013). Emotion regulation in psychopathy. Biological Psychology, 92, 541-548.

Card, N. A., Stucky, B. D., Sawalani, G. M., \& Little, T. D. (2008). Direct and indirect aggression during childhood and adolescence: a meta-analytic review of gender differences, intercorrelations, and relations to maladjustment. Child Development, 79(5), 1185-1229.

Choi, M. H., Lee, S. J., Yang, J. W., Kim, J. H., Choi, J. S., Kim, H. S., ... \& Chung, S. C. (2011). An analysis of the correlation between young male's personal aggression and their skin conductance levels during exposure to aggression images. Psychiatry Research, 186, 441-442.

Crick, N. R., \& Grotpeter, J. K. (1995). Relational aggression, gender, and social-psychological adjustment. Child Development, 66, 710-722.

Cui, Y., Robinson, J. D., Versace, F., Lam, C. Y., Minnix, J. A., KaramHage, M., ... \& Conciripini, P. M., (2012). Differential cigaretterelated startle cue reactivity among light, moderate, and heavy smokers. Addictive Behaviors, 37, 885-889.

Delgado, L. C., Guerra, P., Perakakis, P., Mata, J. L., Pérez, M. N., \& Vila, J. (2009). Psychophysiological correlates of chronic worry: cued versus non-cued fear reaction. International Journal of Psychophysiology, 74, 280-287.

Engelmann, J. M., Gewirtz, J. C., \& Cuthbert, B. N. (2011). Emotional reactivity to emotional and smoking cues during smoking abstinence: potentiated startle and P300 suppression. Psychophysiology, 48, 1656-1668.

Eysenck, H. J., \& Eysenck, S. B. G. (1975). Manual of the Eysenck Personality Questionnaire. London: Hodder \& Stoughton.

Gantiva, C., Estupiñan, E., Montaña, I., Sierra, M., Zocadegui, E., \& Romo-González, T. (2014). Emotional dimensions in aggressive people: differences to affective visual stimuli. Trends in Psychiatry and Psychotherapy, (in press).

Gantiva, C., Guerra, P., \& Vila, J. (2011). Validación colombiana del sistema internacional de imágenes afectivas: evidencias del origen transcultural de la emoción. Acta Colombiana de Psicologia, 14(2), 103-111.

Garner, M., Clarke, G., Graystone, H., \& Baldwin, D.S. (2011). Defensive startle response to emotional social cues in social anxiety. Psychiatry Research, 186, 150-152.

Geniole, S. N., Carré, J. M., \& McCormick, C. M. (2011). State, not trait, neuroendocrine function predicts costly reactive aggression in men after social exclusion and inclusion. Biological Psychology, 87, 137-145.
Gower, A. L., \& Crick, N. R. (2011). Baseline autonomic nervous system arousal and physical and relational aggression in preschool: the moderating role of effortful control. International Journal of Psychophysiology, 81, 142-151.

Grillon, C., \& Baas, J. (2003). A review of the modulation of the startle reflex by affective states and its application in psychiatry. Clinical Neurophysiology, 114, 1557-1579.

Hess, N. H., \& Hagen, E. H. (2006). Sex differences in indirect aggression: psychological evidence from young adults. Evolution and Human Behavior, 27, 231-245.

Kashdan, T. B., Adams, L., Read, J., \& Hawk, L., Jr. (2012). Can a one-hour session of exposure treatment modulate startle response and reduce spider fears? Psychiatry Research, 196, 79-82.

Lang, P., Bradley, M. M., \& Cuthbert, B. N. (2008). International affective picture system (IAPS): affective ratings of pictures and instruction manual (Technical Report A-8). Gainesville, FL: University of Florida.

Lang, P. J., Davis, M., \& Öhman, A. (2000). Fear and anxiety: animal models and human cognitive psychophysiology. Journal of Affective Disorders, 61, 137-159.

Loeber, R., \& Hay, D. (1997). Key issues in the development of aggression and violence from childhood to early adulthood. Annual Review of Psychology, 48, 371-410.

Montoya, E. R., Terbug, D., Bos, P. A., \& van Honk, J. (2012). Testosterone, cortisol, and serotonin as key regulators of social aggression: a review and theoretical perspective. Motivation and Emotion, 36(1), 65-73.

Muñoz, M. A., Idrissi, S., Sánchez-Barrera, M. B., FernándezSantaella, M. C., \& Vila, J. (2013). Tobacco craving and eyeblink startle modulation using 3D immersive environments: a pilot study. Psychology of Addictive Behaviors, 27(1), 243-248.

Muñoz, M. A., Viedma-del-Jesus, M. I., Fernández-Santaella, M. C., Peralta-Ramírez, M. I., Cepeda-Benito, A., \& Vila, J. (2010). Assessment of tobacco craving by means of the affective image visualization paradigm. Motivation and Emotion, 34(1), 93-103.

Patrick, C. J., Bradley, M. M., \& Lang, P. J. (1993). Emotion in the criminal psychopath: startle reflex modulation. Journal of Abnormal Psychology, 102, 82-92.

Peterson, C. J., \& Harmon-Jones, E. (2012). Toward an understanding of the emotion-modulated startle eyeblink reflex: the case of anger. Psychophysiology, 49, 1509-1522.

Reuter, M., Netter, P., \& Janke, W. (2003). Personality and reciprocal inhibition theory: the link between aggression and sexual reactivity. Personality and Individual Differences, 35, 1765-1782.

Roberton, T., Daffern, M., \& Bucks, R. S. (2012). Emotional regulation and aggression. Aggression and Violent Behavior, 17, 72-82.

Rothemund, Y., Ziegler, S., Hermann, C., Gruesser, S. M., Foell, J., Patrick, C. J., \& Flor, H. (2012). Fear conditioning in psychopaths: event-related potentials and peripheral measures. Biological Psychology, 90, 50-59.

Salmivalli, C., Kaukiainen, A., \& Lagerspetz, K. (2000). Aggression and sociometric status among peers: do gender and type of aggression matter? Scandinavian Journal of Psychology, 41, 17-24.

Sánchez-Martín, J. R., Azurmendi, A., Pascual-Sagastizabal, E., Cardas, J., Braza, F., Braza, P., ... \& Munoz, J.M. (2011). Androgen levels and anger and impulsivity measures as predictors of physical, verbal and indirect aggression in boys and girls. Psychoneuroendocrinology, 36, 750-760.

Stanger, N., Kavussanu, M., Willoughby, A., \& Ring, C. (2012). Psychophysiological responses to sport-specific affective pictures: a study of morality and emotion in athletes. Psychology of Sport and Exercise, 13, 840-848.

Wilson, G. D. (1997). Gender differences in sexual fantasy: an evolutionary analysis. Personality and Individual Differences, $22(1), 27-31$. 